\title{
Palma y las veladas literarias en la casa de Juana Manuela Gorriti: un espacio literario y de socialización en Lima (1876-1877)
}

\author{
Carlos Alberto Pérez Garay \\ Instituto Ricardo Palma \\ charlyx333@hotmail.com \\ Lima-Perú
}

\section{Resumen}

El presente trabajo se centra en la relación amical entre el autor de las Tradiciones peruanas y la escritora argentina Juana Manuela Gorriti, originadas en la década de 1850; y en las reuniones celebradas en la casa de esta última, en la ciudad de Lima, entre los años de 1876 y 1877. Trataremos de conocer el espacio literario y de socialización desarrollado en esa tertulia.

Palabras Clave: Ricardo Palma, Juana Manuela Gorriti, Veladas literarias, Literatura, Espacio de socialización.

\section{Abstract}

The present work focuses on the friendship originated in the 1850s between the author of Peruvian Traditions and the Argentinean writer; and in the meetings held at the Argentinian writer's house in the city of Lima between the years 1876 and 1877. We will try to get to know the literary and socialization space developed in that gathering.

Keywords: Ricardo Palma, Juana Manuela Gorriti, Literary evenings, Literature, Socialization space. 


\section{Carlos Alberto Pérez Garay (Perú)}

Licenciado en Historia por la Universidad Nacional Mayor de San Marcos, con estudios de maestría. Docente e investigador. Ha participado como ponente y conferencista en importantes eventos académicos en el país. Ejerce la docencia en la Universidad Ricardo Palma, en el Programa de Estudios Básicos (PEB) y en la Facultad de Ciencias Económicas y Empresariales. Es especialista en temas de historia política, intelectual y literaria. Sus trabajos aparecen en artículos de revistas especializadas y en un libro sobre el tradicionista: Liberalismo criollo, Ricardo Palma, ideología y política (1833-1919), publicado en Lima, 2015. 


\section{Introducción}

Al retirarse de la política activa en 1873, Ricardo Palma retornó nuevamente a la actividad literaria, dedicándose casi por completo a escribir muchas de sus tradiciones. La exitosa publicación de la primera serie de las Tradiciones peruanas en 1872 fue determinante para que el escritor limeño, de cuarenta años, reinicie su encuentro con el papel, la pluma y la tinta a fin de seguir brindando sus originales creaciones a sus numerosos lectores del Perú y de Hispanoamérica.
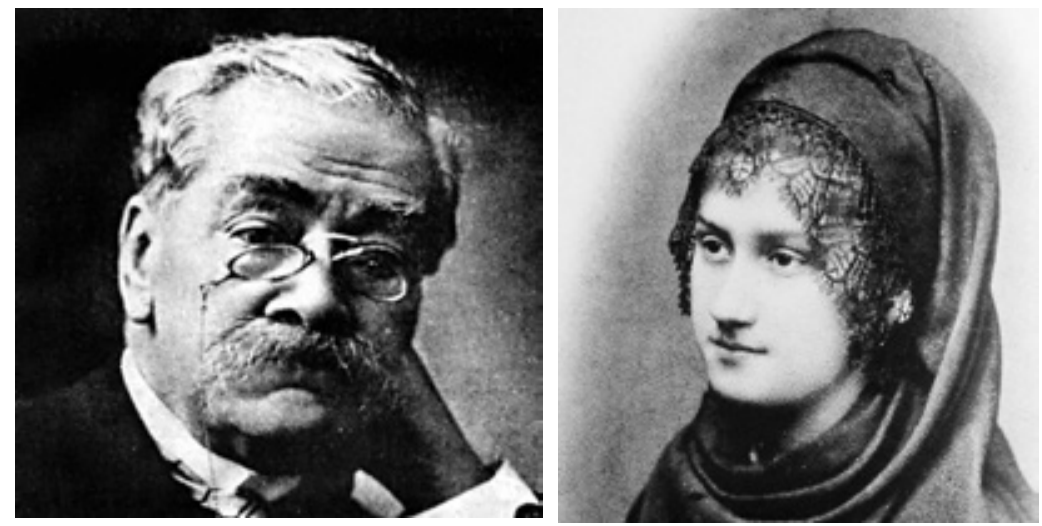

Ricardo Palma y Juana Manuela Gorriti.

Fuente: 1). Archivo Courret-Biblioteca Nacional del Perú.

2). Diario El Clarín. Buenos Aires Argentina.

Fruto de su actividad literaria, aparecerán en importantes publicaciones locales y extranjeras un vasto número de sus tradiciones, ensayos y poemas. El principal órgano difusor de la obra de Palma, en la década de 1870, fue el semanario El Correo del Perú (1871-1878), publicación limeña cuyo propietario era Manuel Trinidad Pérez, uno de los recordados miembros de la «bohemia limeña» y autor en 1862 del drama La industria y el poder. En este semanario, Palma colaboró con 
varias producciones, compartiendo páginas junto a destacados intelectuales como Francisco de Paula Gonzales Vigil, Constantino Carrasco, Carolina Freyre de Jaimes y Pedro Paz Soldán y Unanue (Basadre, 2005, vol. 8, p. 137).

Al parecer, el escritor limeño tuvo la firme intención de recuperar el tiempo desperdiciado en la actividad política, por ello trató de estar más involucrado con el campo literario. Precisamente, por ello, como muchos de sus colegas de pluma, acudió con frecuencia a las diversas veladas literarias que se llevaban a cabo en la capital. Uno de esos centros de reunión a los cuales logró acudir habitualmente fue el Club Literario de Lima, lugar en donde muchas veces llegó a leer de algunas de sus tradiciones, por el año de $1874 .{ }^{1}$ Sin embargo, el principal espacio literario que logró acaparar su atención por aquella década, y a la que asistía de manera frecuente, fue la casa de una de sus mejores amigas: la escritora y periodista argentina Juana Manuela Gorriti, ubicada en la calle Urrutia.

\section{Los lazos de amistad}

La amistad entre Palma y Gorriti databa desde los primeros años de la década de 1850, cuando la escritora argentina decidió radicar en la capital del Perú, tras dejar la ciudad de La Paz, a raíz de su ruptura matrimonial con el presidente boliviano, el general Manuel Isidoro Belzu. A su llegada a Lima, Gorriti abrió en su casa una escuela mixta primaria. Asimismo, en su residencia fundó un salón literario, donde muchos limeños amantes de las letras acudían con frecuencia. Por su labor literaria y periodística fue calurosamente acogida por los bohemios y tratada como si fuese uno de ellos. Según recuerda Palma (1964) «Los bohemios la tratábamos con la misma llaneza

l Dos tradiciones de Ricardo Palma dan cuenta de su presencia en dicho club literario: "El poeta de las adivinanzas" y "Ollantay". 
que a un compañero, y su casa era para nosotros un punto de reunión» (p. 1297). El mismo testimonio es corroborado por unas anotaciones de puño y letra del tradicionista encontradas por Oswaldo Holguín en la Biblioteca Nacional del Perú, en donde escribió: «... [desde 1851, su casa] fue el centro de la juventud literaria. A ellos concurríamos con entera llaneza Arnaldo Márquez, Manuel Castillo, Luis Cisneros, Clemente Althaus, Pompilio Llona, Trinidad Fernández, Fernando Velarde, Carlos Salaverry [añadido], Juan Vicente Camacho» (citado en Holguín, 1994, p. 192). Gracias a la estimación que le tuvo, Palma le dedicó en la década de 1850 dos de sus composiciones: «Infernum el hechicero» (1 854) y «La venganza de un ángel» (1857).

$\mathrm{Al}$ iniciarse la década de 1860, la amistad de ambos personajes se hizo más estrecha. Precisamente, los dos tendrán ocasión de escribir en La Revista de Lima, el principal órgano de la elite intelectual criolla limeña. Palma publicó sus primeras tradiciones mientras que Gorriti dio a conocer algunos pequeños relatos, en los que asumió el papel de orientadora moral y de crítica de la sociedad, al defender los derechos de la mujer y la familia.

Precisamente, respecto al último tema, Gorriti cuestionó en su novela Si haces mal, no esperes bien (publicada por entregas desde 1861 en La Revista de Lima) la desintegración de la familia andina por obra de los hacendados, empresarios mineros y comerciantes de la sierra. De acuerdo a Francesca Denegri (1996):

los relatos de Gorriti acerca de las mujeres andinas y los hijos que estas concibieron a resultas de un encuentro explotador, hicieron así trizas el bien ensayado concepto de una esfera privada, en donde hombres y mujeres supuestamente cultivaban sentimientos delicados protegidos de las fuerzas malignas imperantes en el mundo exterior y a la forma auto 
congratulatoria en la que la elite intelectual se refería a las mujeres peruanas (p. 99).

Se vivía por aquel momento el periodo de la prosperidad falaz del guano, y varios políticos e intelectuales anhelaban impacientemente la llegada de la modernización y la ejecución de un vasto programa de obras públicas. La elite económica buscaba por todos los medios el surgimiento de una cultura burguesa en el Perú. Aquella cultura debía de ser de inspiración occidental y adaptada al medio local ${ }^{2}$. Comerciantes, escritores y artistas, fueron el resultado de aquella experiencia burguesa peruana. Cada uno de ellos adoptó un estilo de vida propio, congregándose en importantes espacios de socialización, como cafés, salones literarios y salas de redacción de los diarios.

En 1863, Palma y Gorriti serán los encargados de la sección literaria en el semanario político-literario La República, dirigido por José María Quimper. Sin embargo, para fines de esa década y los primeros años de la década de 1870, la relación entre Palma y Gorriti se volvió menos frecuente debido a que el autor de las Tradiciones andaba completamente abocado a la actividad política, al desempeñarse como secretario privado del presidente José Balta y cumplir funciones parlamentarias como senador por el departamento de Loreto, entre 1868 y 1873.

\section{Las veladas literarias}

Tras liberarse de los vaivenes políticos, Palma volvió a reencontrarse con su queridísima amiga argentina. En su domicilio, la autora de La Quena empezó a celebrar cada quince días sus conocidas veladas literarias nocturnas, las cuales daban cita a numerosos amantes de la literatura ${ }^{3}$. Nombres como

2 Sobre la influencia de la cultura burguesa en la sociedad europea del siglo XIX, véase Gay, P (1992).

3 Para conocer las actividades de la tertulia, véase el libro de Gorriti, J. M. (1892). 
Manuel Adolfo García, Numa Pompilio Llona, Acisclo Villarán, Abelardo Gamarra, Clorinda Matto de Turner, Manuela Villarán, Mercedes Cabello de Carbonera, entre otros, formaron parte de la tertulia de Gorriti.

Las veladas literarias en la casa de Gorriti recibieron una amplia cobertura por parte de la prensa capitalina. En los días previos, los diarios empezaban a preparar el ambiente para las reuniones y al día siguiente de cada velada ofrecían un resumen detallado de lo sucedido. El programa, que solía ser los días miércoles, incluía recitales de poesía, lectura de cuentos y ensayos, ejecuciones en piano y violín de obras musicales tanto cultas como populares (allí se pusieron en boga los yaravíes), interpretación de canciones, juegos y charadas, para terminar en una tertulia que se prolongaba hasta altas horas de la madrugada. De acuerdo a César Salas Guerrero (2006):

durante el lapso en que se desarrollaron las mencionadas veladas (julio de 1876 a julio de 1877) la casa de la escritora fue el centro de la actividad literaria en la capital peruana y lugar de presentación de los escritores hispanoamericanos que llegaban a Lima (p. 92).

Como la mayor parte de los escritores residentes en Lima, Palma acudió a estas veladas, convirtiéndose en uno de los principales protagonistas de este importante cenáculo ${ }^{4}$. Según Oswaldo Holguín (2018):

Palma fue uno de los animadores principales de las veladas y asistió a muchas porque pasaba por un excelente momento de producción intelectual y sus relaciones con la sociedad

Asimismo, consúltese Basadre 1995, vol. 8, pp. 151-152.

4 Una muestra de la amistad entre Palma y su amiga argentina se observa en Gorriti, J. M. (2004). 
culta de Lima no podían ser mejores. Su talento le había ganado un prestigio que los zoilos no podían disminuir. Presentó trabajos en la mayoría de ellas: algunas poesías propias o traducidas de Heine y, sobre todo, numerosas tradiciones, las más originales, las cuales eran muy solicitadas y esperadas (pp. 155-156).

En este lugar, el autor de las Tradiciones logró ceñirse a las reglas de sociabilidad impuestas por la anfitriona argentina ${ }^{5}$. Esta sociabilidad desarrollada al interior de este espacio literario era una norma frecuente que se fue dando en buena parte del siglo XIX, en donde las reglas y códigos fueron configurando la conducta de los individuos de la sociedad (Elías, 1987, p. 128). El afán de reunir a sujetos masculinos y femeninos alrededor de la literatura fue uno de los objetivos de Gorriti, quien además se mostró a favor de una conversación más abierta entre los asistentes de la tertulia. Según la crítica literaria argentina Gabriela Batticuore (1995): «en las veladas no hay expresiones partidarias, pero sí la voluntad explícita y compartida de asumir un rol formador y propagador de nuevas ideas y nuevas costumbres...» (p. 65).

La decisión de Gorriti fue respaldada por varios de los habituales asistentes que se congregaban en su domicilio, entre ellos Ricardo Palma, uno de los principales devotos del libre pensamiento en el Perú. Gorriti fue también una de las abanderadas de los derechos de la mujer. Su posición feminista fue compartida y respetada por el autor de las Tradiciones, quien conocía ampliamente este tema por la enseñanza de su maestro y amigo, el doctor Francisco de Paula Gonzales Vigil, uno de los difusores de la educación de la mujer en el Perú ${ }^{6}$.

5 Sobre este punto, véase Forment, C. (1999).

6 Palma era un abierto defensor de los derechos de la mujer en el Perú; al respecto véase la tradición «Borrasca en un Vaso de Agua» (1964, pp. 1493-1496). El propio tradicionista también se referirá a este tema, al igual que el tema de la 
Así, bajo la influencia de las ideas feministas, la escritora argentina logró blandir su pluma para acusar a la sociedad machista de su tiempo. En 1876, Gorriti había publicado en Buenos Aires Panoramas de la vida: colección de novelas, fantasías, leyendas y descripciones americanas, una recopilación de su obra dispersa en dos volúmenes. En el primero, la autora presentó una de sus mejores novelas: Peregrinaciones de un alma triste, que se constituye una especie de memoria de viaje, abordada desde la perspectiva de una narradora en el marco de una conversación entre dos amigas (Laura y Carmela). En el curso del relato se van introduciendo las historias de otras personas; este tipo de estructura dinamiza la lectura de la obra. Según María Sulca (2008), la escritora argentina:

plantea la adopción de ciertas estrategias discursivas que le permiten al sujeto femenino socavar el orden patriarcal; en otras palabras, se trata de un discurso en el que se articulan dos voces, la primera, es la que se ciñe al discurso hegemónico patriarcal y la segunda es una voz que busca subvertir sutilmente las estructuras de poder de la época (p. 3).

\section{Los últimos años}

Finalizada la tertulia de Gorriti, el 11 de julio de 1877, Palma continuará escribiendo sus famosas tradiciones, esta vez en un nuevo periódico literario fundado por él mismo: La Broma, que de acuerdo a Angélica Palma, apareció por ese mismo año

libertad de pensamiento. Es posible la influencia de Vigil en el pensamiento del autor de las Tradiciones, producto de la gran amistad surgida en la década de 1850, y de sus reiteradas charlas dentro de la labor periodística. Palma debió haber leído el libro del clérigo tacneño Importancia de la educación del bello sexo, donde su autor toca el tema del feminismo. Al respecto véase F. P. Gonzales Vigil (1976). 
(1933, p. 77). En este periódico, el integrante de la generación romántica continuó difundiendo sus composiciones literarias, sin embargo, interrumpirá el ejercicio de la pluma a raíz del estallido de la guerra con Chile en 1879.

Al concluir la guerra del Pacífico, en 1883, Palma reinició su amistad con su gran amiga argentina. En 1884, la autora de $E l$ pozo de Yocci retornó a Argentina, residió primero en Buenos Aires y luego se dirigió a su natal Salta. Desde el país austral, mantuvo una intensa correspondencia epistolar con el reconocido escritor peruano. Precisamente, de esa activa comunicación desplegada por una respetable dama del siglo XIX como Juana Manuela Gorriti, la historiadora francesa Michelle Perrot ha manifestado que «en la escritura y en la palabra, las mujeres están en pie de igualdad con los hombres» (2009, p. 35).

Alejada del Perú, la escritora pasará sus últimos días en su tierra, lejos de ese bullicio limeño y de los pregones de la capital. Antes de su fallecimiento, ocurrido el 6 de noviembre de 1892, Gorriti estuvo muy pendiente de su amigo peruano, llegándole a desear, por medio de las cartas, el mayor de los éxitos en su cada vez más ascendente carrera literaria.

\section{Referencias bibliográficas}

Basadre, J. (2005). Historia de la República del Perú. 1821-1933. Lima: Orbis, vol. 8.

Batticuore, G. (1999). El taller de la escritora. Veladas literarias de Juana Manuela Gorriti. Lima-Buenos Aires (1876 - 1892). Buenos Aires: Beatriz Viterbo editora.

Denegri, F. (1996). El abanico y la cigarrera. La primera generación de mujeres ilustradas en el Perú. 1860-1895. Lima: Flora Tristán /Instituto de Estudios Peruanos. 
Elías, N. (1987). El proceso de civilización. Investigaciones sociogenéticas y psicogenéticas. México D. F.: Fondo de Cultura Económica.

Forment, C. (1999). «La sociedad civil en el Perú del siglo XIX: democrática o disciplinaria». En Hilda Sábato. Ciudadanía política y formación de naciones. Perspectivas históricas de América Latina. México: FCE.

Gay, P. (1992). La experiencia burguesa. De Victoria a Freud. La educación por los sentidos. I. México: Fondo de Cultura Económica.

Gonzales Vigil, F. P. (1976). Importancia de la educación del bello sexo. Editado con prólogo de Helen Orving de Salazar. Lima: Instituto Nacional de Cultura.

Gorriti, J. M. (2004). Cincuenta y tres cartas inéditas a Ricardo Palma. Fragmentos de lo intimo. Buenos Aires-Lima, 1882-1891. Edición crítica. Estudio preliminar de Gabriela Batticuore. Lima: Universidad de San Martín de Porras, Escuela de Turismo.

Gorriti, J. M. (1892). Veladas literarias de Lima 1876-1877. Buenos Aires: Impr. Europea.

Holguín, O. (2018). «Notas sobre la complicidad intelectual de Ricardo Palma y Juana Manuela Gorriti». En Aula Palma, (XVII), pp. 141-177. Lima: Universidad Ricardo Palma.

Holguín, O. (1994). Tiempos de infancia y bohemia. Ricardo Palma (18331860). Lima: Pontificia Universidad Católica, Fondo Editorial.

Palma, A. (1933). Ricardo Palma. Buenos Aires: Editorial Cóndor.

Palma, R. (1964). Tradiciones Peruanas Completas. Madrid: Aguilar, 1964.

Perrot, M. (2009). Mi historia de las mujeres. Buenos Aires: Fondo de Cultura Económica. 
Salas Guerrero, C. (2006). «Juana Manuela Gorriti y el Perú». En Revista de la Casa Museo Ricardo Palma, (6), pp. 87-102, Lima.

Sulca Muñoz, M. J. (2008). Juana Manuela Gorriti y las mascaradas de la femineidad. Tesis para optar el título de Licenciada en Literatura y Lingüística con mención en Literatura Hispánica. Lima. Pontificia Universidad Católica del Perú. Facultad de Letras y Ciencias Humanas.

Recibido el 28 de setiembre de 2020 Aceptado el 28 de octubre de 2020 